\title{
Compensation for subjects of medical
} research: the moral rights of patients and the power of research ethics committees

\author{
Stephen Guest University College, London
}

\begin{abstract}
Awareness of the morally significant distinction between research and innovative therapy reveals serious gaps in the legal provision for compensation in the UK for injured subjects of medical research. Major problems are limitations inherent in negligence actions and a culture that emphasises indemnifying researchers before compensating victims. Medical research morally requires compensation on a no-fault basis even where there is proper consent on the part of the research subject. In particular, for drug research, there is insufficient provision in the current patient guidelines of the Association of the British Pharmaceutical Industry, since they make "no legal commitment" to paying compensation for injury to patient subjects. There is a need for the provision of both adequate insurance and contractual arrangements for making payments. The solution is for Local Research Ethics Committees (LRECs) to make use of their power to withhold approval of medical research where compensation is not legally enforceable.
\end{abstract}

\section{Definition of research and the general principles}

THE DEFINITION OF RESEARCH

We might begin with the Oxford English Dictionary's definition. "Research" is there defined as "An investigation directed to the discovery of some fact by careful study of a subject; a course of critical or scientific discovery". The important point is that it is accompanied by an intention to further knowledge, irrespective of benefit to the subject. This essentially captures the idea of research used by the Royal College of Physicians (RCP). ${ }^{1}$ The crucial component is the intention with which the research is done since there are clearly novel ways in which techniques (or drugs) may be used, especially in cases where there is a high risk in any case that a patient will die, and

\section{Key words}

ABPI guidelines; negligence actions; LRECs; drug research; compensation; innovative therapy; research on patients;research on healthy volunteers; NHS indemnity. where it is justifiable to use some less orthodox treatment; in such cases, the experimental spin-off is only secondary to the intention to benefit the patient. Research therefore begins where benefit to the patient becomes only secondary. It is therefore different from innovative therapy, where the aim is "entirely for the benefit of a particular individual patient". ${ }^{2}$ Although not clearly established in English law, Canadian law clearly accepts the distinction: Zimmer $\mathrm{v}$ Ringrose. ${ }^{3}$ As the RCP points out, innovative treatment may become part of medical practice without becoming the subject of formal research.

THE JUSTIFICATION OF THE BENEFIT TO OTHERS This is an important justification for energetically pursuing medical research. But it essentially means that research subjects are being used for the benefit of others; a point not to be overshadowed by the fact that they consent. It is unfair to them if they are expected to bear a disproportionate loss in the case of mishap. Here it is salutary to keep thalidomidetype tragedies, where the consequences are so drastic, in mind. To employ sensible philosophical terminology, research subjects possess rights which cannot simply be balanced against the general welfare of society even where the subjects appear to consent. This can be seen in the moral futility of denying duty to a severely injured research subject by saying: "you consented to taking the drug; you knew it was a new drug and that its effects were not fully known".

A general limitation to consent to harm to yourself exists in the criminal law and although there is an exception for surgical interventions these have to be justifiable. ${ }^{4}$ It would therefore beg the question to say that all research where consent was obtained was for that reason legally justified. It is useful to note the Helsinki Declaration of the World Medical Association in 1964, speaking for the patient subject of research on the point: "The physician can combine medical research with professional care ... only to the extent that medical research is justified by its potential diagnostic or therapeutic value for the patient" and (speaking for the healthy subject of research) "the interest of science and society should 
never take precedence over considerations related to the wellbeing of the subject". It follows that, because there is a risk that research may focus insufficiently on a research subject's moral rights, injury caused through research raises special considerations distinct from those applying to ordinary patient care. $^{5}$

Of course, medical research risks cover a wide range down to the case where the harm and risk are de minimis. Many trials do not create risks of injury at all (measuring heartbeat or breathing rate), and compensation will not be necessary where there is even a high risk of negligible injury (minor shortterm painless bruising). In these undramatic cases consent really does remove any requirement to pay compensation.

\section{HEALTHY (NON-PATIENT) SUBJECTS AND PATIENT SUBJECTS}

It is important to draw this distinction for several reasons. They involve different types of study, different types of recruitment and, importantly, different risks. With seriously ill patients, because of the higher risks which it seems justifiable to take, research can join more closely with innovative treatment to the point where the two merge, perhaps indistinguishably.

In my view, all research must be subject to the same principles and the fact that the subject is a patient only alters the degree of risk which the researcher may reasonably request from the subject. See, for example, the statement by the Royal College of Physicians that "the same general principles and arrangements should apply in clinical trials involving patients as those described . . . for healthy volunteer studies". ${ }^{6}$ This wisely echoes the Pearson Report on civil liability for personal injury which singled out medical research as an area of particular concern and took the view that a patient was in the same position as a healthy person volunteering to take part in research. ${ }^{7}$

\section{Compensating the injured subject}

THE SPECIAL POSITION OF RESEARCH WITH DRUGS

Early uses of drugs are a special case and remind us of the thalidomide experience. The Medicines Act 1968 controls medicines for research on patients. Licences are not required for research on healthy volunteers. The governing body is the Medicines Control Agency (MCA) which licenses drugs. The main categories are product licences, for which variations for new uses may be granted, and clinical trial certificates (CTCs) from which exemptions for new uses may also be granted (CTXs, or DDXs - exemptions granted to doctors and dentists). The CTX scheme is now the usual means of gaining drug clearance and was introduced in 1981 following complaints from the pharmaceutical companies about complexity and time delay ("drug lag") in granting variations to product licences, and in issuing CTCs. For a CTX only a summary of the? data requirements is needed and the fundamental test used by the CTX panel acting for the MCA $\stackrel{\text { क }}{+}$ appears to be the negative one of whether on the provided information the testing of the medicine $\overline{\bar{c}}$ "would not involve a serious risk to the trial subject".

Nevertheless, drugs are not entirely within $a \varrho$ special category and their experimental use shouldes be compared to novel surgical and other medical -5 techniques. The increasing use of keyhole surgery, the developing use of lasers, sometimes combinedw with photo-sensitive drugs, ultrasound and radio $\frac{?}{2}$ active isotopes, fall within the same general scope of research. The Department of Health is presentlyi considering a licensing body and scheme similar tow the MCA for this wider category.

DIFFICULTIES WITH THE TORT OF NEGLIGENCE

A primary problem is access to justice through the expensive and time-consuming adversarial process. But this is only the beginning. In the UK the plain- $\Phi$ tiff must establish both that the researcher caused $\overrightarrow{0}$ the injury and that he/she was negligent in doing so. But causation is notoriously difficult to prove in medical negligence actions because it is relativelyo easy to suggest that other causes were predominant. That is particularly so where a research subject dieso shortly after an experiment. No-fault schemes in尺 countries such as Sweden and New Zealand have been seriously undermined because under theo schemes causation still has to be proved. Indeed, "no-fault" is an unhappy title, since finding fault is also part of the necessary process of establishing. causation, the test being not only "but for" the researcher's action the subject would not have been injured but that the injury was "reasonably foresee-3. able in the ordinary course of events". There is one difference between the ordinary case and medicaB research although perhaps it should not be overes-o timated. It is that an injured subject cannot easily? claim that a risk was "reasonably foreseeable in theo ordinary course of events", because the nature of experiment is such that a. unforeseeable events are to be expected and $b$. there is an inherent difficulty 0 in establishing what the "ordinary course of events" actually is.

As far as proving negligence goes, the standard of care required causes particular problems in the case of research into alternative means of treatment; after all, the researcher is trying by his research to establisho new standards of care. Of more concern since it is, the situation that most frequently arises in practice $\mathbb{\Omega}^{\mathbb{D}}$ is the standard of care relating to the obtaining of consent. Without doubt, full consent should be obtained. Even the "therapeutic" privilege in nof obtaining full consent, justified on the ground thaf the patient's anxiety might exacerbate his condition, ${ }^{8}$ cannot apply to research subjects. If the patient is in too delicate a state to be told the 
consequences of medical intervention he should not be a subject of research. ${ }^{9}$

The availability of compensation in practice arises predominantly through two sources; the so-called National Health Service (NHS) indemnity and through medical insurance associations. As far as the NHS is concerned, recent arrangements protect NHS employees from claims in negligence in performing local health authority duties of which, for many, research is one. ${ }^{10}$ It should be noted that the trusts are required to pay any claims out of their own resources, although there is provision for trusts to be given loans from the regional health authority for this purpose. But the NHS does not cover the nonnegligent cases other than through the unwieldy and uncertain ex gratia payments which the NHS is empowered to make subject to $\mathrm{DoH}$ and Treasury approval. ${ }^{11}$ It is important to see how the indemnity is viewed by the DoH. The guidelines which introduce the new arrangements speak exclusively in terms of how payments for claims are to be divided between the health authority and other bodies such as sponsoring institutional or corporate bodies and not in terms of compensation to an injured party. Indeed, the culture of thinking about compensation is weighted towards the protection of the researcher, etc, rather than towards the protection of the injured party. Evidence, for example, is in the DoH's 1991 guidance for LRECs which contemplates that members should not be indemnified for "gross negligence". ${ }^{12}$ This is a clear indication that the circular did not consider compensation for the injured subject as the paramount principle because it would follow that if the LREC were grossly negligent there would not be $\mathrm{DoH}$ financial backing and so nothing by way of compensation.

Outside the NHS, institutions such as the Medical Defence Union and a number of other such associations (nurses, physiotherapists, dentists, etc) protect their members against events widely characterised as "legal liability". The question of compensation thereby centres naturally on the extent of the researchers' professional obligations to their patients and, where applicable, to their research subjects. In practice, the MDU and other associations assume the responsibility for a member's legal liability and indemnify the member for the costs. As with the NHS, although perhaps more understandably, the emphasis lies on indemnifying the member rather than protecting an injured party.

\section{THE CONSUMER PROTECTION ACT 1987}

The notorious difficulty with establishing liability is the "state of the art" defence which the act incorporates, ${ }^{13}$ a particularly pressing problem when the whole point of the medical research is to determine facts which necessarily go beyond what is currently part of "the state of the art". In the case where the product is "defective", and has caused harm, there is entitlement to compensation under the act. An advantage is that the liability is strict, that is, is not at first sight dependent on fault on the part of the producer although there is perhaps a fault element in proving that a product is defective. But the wellknown drawback with the remedy is the producer's defence of development risk. Where the current state of scientific knowledge at the time the product was produced would not have revealed the defect the producer is not liable. Given that research attempts to discover what is beyond the current state of knowledge, the injured research subject is not in a strong position.

\section{COMPENSATION RIGHTS ARISING THROUGH \\ CONTRACTS OR INSURANCE}

A difficulty is that there is no general requirement upon any person or body to take out insurance to protect research subjects and the $\mathrm{DoH}$ made it clear in 1991 that NHS bodies are not empowered to offer advance indemnity to participants in research projects. ${ }^{10}$ Some institutions, such as a number of universities and research centres do take out insurance but the practice is not by any means universal. For drug research on healthy volunteers, the Association of the British Pharmaceutical Industry (ABPI) recommends to its members that no-fault liability "in the event of injury" and on proof of causation, should be accepted by the sponsoring company as part of a legally binding contract between the researcher (acting as agent for the company) and the subject. ${ }^{14}$

\section{ABPI guidelines for patients}

On the other hand, the ABPI recommends members to compensate patient subjects of research for "more serious injury of an enduring and disabling character (including exacerbation of an existing condition) and not for temporary pain or discomfort or less serious or curable complaints", on a no-fault basis although "without legal commitment". ${ }^{15}$ Perhaps reasonably they restrict liability to pre-marketed drugs or marketed medical medicines which are being tested for use other than that in the product licence. Clearly, these guidelines are intended (unlike the healthy volunteer guidelines) not to have legal force and it would be difficult to establish a contract in the absence of an express agreement with the patient. Particularly, it would be almost impossible to establish the necessary "contractual intention" because of the "without legal commitment" wording. The ABPI has met with criticism of this provision but maintains that its members would in reality pay out; that the cases are rare; and that there are problems inherent in establishing a legal contract with a patient, such as the compos mentis of the patient and the special doctor/patient relationship. ${ }^{16}$

These three arguments are not particularly strong. Drug injuries can be very expensive to compensate, as the thalidomide tragedy proved, and it is an unsatisfactory position for the injured subject that 
184 Compensation for subjects of medical research: the moral rights of patients and the power of research ethicsc committees

the research sponsor be faced with balancing cost against breaching a legally non-enforceable albeit moral undertaking. It seems conceivable to me that, in some events, a sponsoring company, or its overseas controlling company, might well decide that the costs are simply not worth it. The argument that the cases would be rare carries no weight since if injury occurs compensation is required; in any case, since the guidelines envisage paying compensation, they must, too, envisage the event of injury. If the third argument means that there might be patients too ill to make a contract, then they will almost certainly be too ill to consent to research. Perhaps carrying more weight is the argument that making the researcher a contractor would intrude inappropriately into the doctor-patient relationship. But why? The doctor must have the patient's best interests at heart as part of his general duty to provide patient care, and it is clearly in the patient's interest to have adequate compensation arrangements in place. In any case, what is necessary would not be a formal document like a will or a mortgage deed but a relatively simple addition to the patient's consent form. ${ }^{17}$

\section{The powers of Local Research Ethics Committees}

These committees now substantially control research. There are a large number, all of which are guided by a $1991 \mathrm{DoH}$ circular. ${ }^{18}$ But the circular does not have legal force. Local Research Ethics Committees broadly cover NHS research within their geographical area, and non-NHS research submitted by agreement, and they are to be regarded as independent ("not beholden to" the NHS bodies). The important (indeed, crucial) point is that "No NHS body should agree to a research proposal without the approval of the relevant LREC" and so approval can be made conditional upon compensation. ${ }^{19}$ It is within the power of a LREC, therefore, to make its consent to research conditional upon adequate compensation arrangements being in place. The statement in the RCP guidelines that "there is little that RECs can do" about the unsatisfactory situation regarding compensation is therefore false. ${ }^{20}$ The power to require compensation, too, is frequently exercised and evidence for this is the common practice of LRECs to make it a requirement that sponsoring companies which are not members of the ABPI should comply with the ABPI guidelines.

Should there be positive vetting by the LREC of the safety of drugs? There is anecdotal evidence that the CTX panel takes the view that the onus lies on the LREC because of the speeded-up test for granting a CTX certificate. ${ }^{21}$ Further, the RCP states that the CTX (or CTC or DDX) status "does not imply that the ethics of the investigation have been subject to significant review and in no way reduces the duties of RECs". ${ }^{22}$

\section{Conclusions}

There should be explicit recognition by all those in charge of medical research of the moral importance of treating compensation of the injured $\stackrel{\bar{F}}{+}$ research subject as paramount. In effect, this means adopting a principle of no-fault compensa-음 tion and recognition would veer the indemnity $\frac{\bar{\sigma}}{\vec{\Phi}}$ culture towards a compensation culture. All $\stackrel{\mathbb{Q}}{\Omega}$ LRECs should lobby the ABPI for their patient guidelines to be made identical to its healthy vol- $\rightarrow$ unteer guidelines. In the meantime, LRECs should ${ }_{-}^{\circ}$ require that research information sheets contain $\vec{\omega}$ clear information concerning lack of legal rights to compensation so that the issue becomes clearly part of the research subject's overall consent. N Finally, LRECs should be fully prepared, where ${ }_{\omega}^{\omega}$ risks are more than negligible, to refuse consent when legally enforceable no-fault compensation is $\stackrel{\infty}{-}$ lacking.

Stephen Guest, BA, LLB, BLitt, PhD, is Reader in Legal Theory in the Faculty of Laws, University College, London and a Legal Member of University College and $-\vec{c}$ Hospital Committee (Alpha) on the Ethics of Medicake Research.

\section{Acknowledgement}

I thank members of the Medical Ethics and Law: Conference at University College London in February, 1995, for helpful comments.

\section{References and notes}

1 Royal College of Physicians. Guidelines on the practice of ethics committees in medical research involving humand subjects [3rd ed]. London: Royal College of Physicians, 1996: para. 6.4.

2 See reference 1: para. 6.5 .

3 (1981) 124 DLR (3d) 215 (Alberta CA).

4 See $R v$ Brown [1994] 1 AC 212: 282 and 266.

5 See reference: 1 . Also see: Royal Commission on Civi? Liability and Compensation for Personal Injury (theo "Pearson report"), cmnd 7054 1978, para 1339; and. see: Neuberger J. Ethics and health care. King's Fund Institute Research Report 13, 1992.

6 See reference 1: para 9.15 .

7 See reference 5: para 1340.

8 See Lord Scarman in Sidaway $v$ Board of Governors $Q \mathbb{P}$ the Bethlem Royal Hospital, etc [1985] 1 AC 871: 888-90

9 Note the admirably expressed statement of principle in s 10 of the New Zealand Bill of Rights 1990: "Every person has the right not to be subjected to medical or scientific experimentation without that person's consent".

10 Department of Health. Local Research Ethic Committees. London, 1991. OHSG(91)5.

11 See reference 10: para 3.

12 See reference 10: para 2.11.

$13 \mathrm{~S} 4(1)$ (e) states that it is a defence “... that the state of scientific and technical knowledge at the relevant time was not such that a producer of products of the sams description as the product in question might be $\mathrm{e}^{+}$ 
expected to have discovered the defect if it had existed under his products if they were under his control ...".

14 Association of the British Pharmaceutical Industry. Guidelines for medical experiments in non-patient human volunteers. London: ABPI, 1990. (1988, revised 1990).

15 Association of the British Pharmaceutical Industry. Clinical trial compensation guidelines. London: ABPI, 1991.

16 In correspondence with the UCL Research Ethics Committee.

17 I am grateful to Professor Aubrey Diamond QC for this point.

18 Following an EC directive: EC (1991). Updated standards for the testing of medicines for human use. 91/507/EEC.

19 But see Marshall T, Moodie P. Scrutinising research ethics committees. British Medical fournal 1988; 297: 753. They say that there is no "absolute" requirement. In the sense that there is no statutory requirement, this is true, but there are duties of employment arising from $\mathrm{DoH}$ circulars, letters of intent and other evidence of established practices which are reasonably sufficient to impose the requisite legal duty. It is that those hospital administrators who are ultimately responsible for giving permission for medical experiments, especially in allocating resources, should first ensure that approval has been given by the local ethics committee.

20 See reference 1: para 9.3.

21 I thank my research student, Caroline Wilson, for this point.

22 See reference 1: para A1.15. 